\title{
Mode-Group Selective Air-Clad Photonic Lantern
}

Mariam Mathew, Neethu; Grüner-Nielsen, Lars; Usuga Castaneda, Mario A.; Galili, Michael; Rottwitt, Karsten

Published in:

Frontiers in Optics 2018

Publication date:

2018

Document Version

Publisher's PDF, also known as Version of record

Link back to DTU Orbit

Citation (APA):

Mariam Mathew, N., Grüner-Nielsen, L., Usuga Castaneda, M. A., Galili, M., \& Rottwitt, K. (2018). Mode-Group Selective Air-Clad Photonic Lantern. In Frontiers in Optics 2018 [Paper FTu5B.4] Optical Society of America (OSA).

\section{General rights}

Copyright and moral rights for the publications made accessible in the public portal are retained by the authors and/or other copyright owners and it is a condition of accessing publications that users recognise and abide by the legal requirements associated with these rights.

- Users may download and print one copy of any publication from the public portal for the purpose of private study or research.

- You may not further distribute the material or use it for any profit-making activity or commercial gain

- You may freely distribute the URL identifying the publication in the public portal

If you believe that this document breaches copyright please contact us providing details, and we will remove access to the work immediately and investigate your claim. 


\title{
Mode-Group Selective Air-Clad Photonic Lantern
}

\author{
Neethu M. Mathew ${ }^{1}$, Lars Grüner-Nielsen ${ }^{2}$, Mario A. U. Castaneda ${ }^{1}$, Michael Galili ${ }^{1}$ \\ and Karsten Rottwitt ${ }^{1}$ \\ ${ }^{I}$ DTU Fotonik, Ørsteds Plads, building 3432800 Kgs. Lyngby, Denmark \\ ${ }^{2}$ Danish Optical Fiber Innovation, Åvendingen 22A, 2700 Brønshøj, Denmark \\ namama@fotonik.dtu.dk
}

\begin{abstract}
A new method for fabrication of mode group selective photonic lanterns is experimentally demonstrated. The design is very simple, using only a tapered fiber bundle and an air-cladding. Good mode group selectivity is demonstrated.
\end{abstract}

OCIS codes: (060.2340) Fiber optics components, (060.4230) Multiplexing.

\section{Introduction}

Photonic Lanterns (PL) is a promising mode multiplexer technology which allows simultaneous (de)multiplexing of several modes, potentially with low loss and high mode selectivity [1]. A new fabrication technique for PL has been reported [2]. In this technique the input fibers of the lantern are stranded together, (without using a capillary tube) down-tapered, spliced to the output few mode fiber, and finally coated with a polymer with lower refractive index than the cladding of the fibers. In [2] no mode selectivity was demonstrated. Here we demonstrate a mode group selective lantern. Furthermore, it is shown that the polymer cladding can be exchanged with an air cladding. Getting rid of the polymer coating not only make the fabrication simpler and cheaper, but also gives lower loss, as our current polymer coating method is found to add loss.

\section{Design}

A mode-group selective lantern for $\mathrm{LP}_{01}$ and the $\mathrm{LP}_{11}$ mode groups for a OFS two mode step index fiber (TMF) is designed using a standard single mode fiber (SSMF) and two low cut off fibers (Corning HI1060). The performance of the PL has been modeled using a 2D-scalar mode solver. The scalar approximation is expected to give some error on the results due to the very high index contrast between silica and air. However, such a model is used to get the general trends and the obtained results agree well with the experimental results. The simulation results are summarized in Fig 1. The evolution of the first 6 lantern modes along down taper is shown in Fig 1(a). Lantern mode 1 starts in the SSMF,

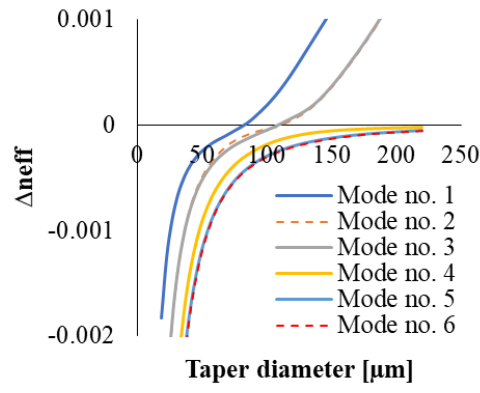

(a)

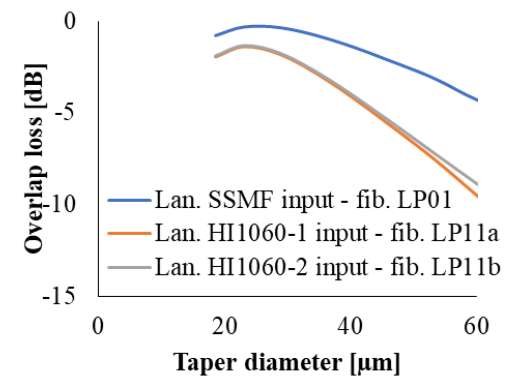

(b)

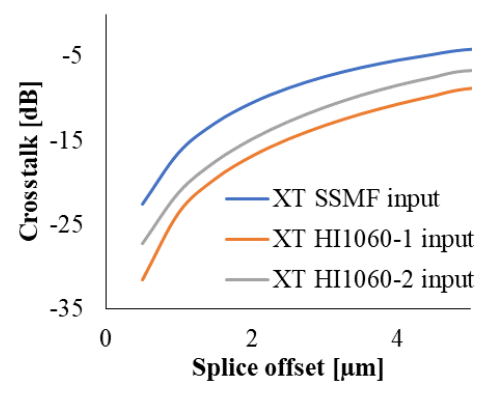

(c)

Fig. 1. Result of simulations. a) effective index difference versus taper diameter. b) Coupling loss between end of taper and two mode fiber due to mismatch in mode distributions. c) Effect of offset in the coupling of taper end and two mode fiber on mode crosstalk.

while modes 2 and 3 start in the HI1060 fibers. Mode 4 and up are unused (guided) cladding modes. If the difference between the effective index is sufficiently large and the down taper is sufficiently slow, the power stays within the 
mode, i.e. the power coupled into the SSMF stays in mode 1 while the power coupled to the two HI1060 stays within modes 2 and 3. The calculated loss from the coupling between the taper end and the two mode fiber is shown in fig 1(b). The loss is observed to be minimum for a taper diameter around $23 \mu \mathrm{m}$. Offset in the coupling between the taper and two mode fiber is a source of loss [2]. Fig 1(c) shows the simulated effect of this offset on crosstalk. Generally, the crosstalk is higher for the $\mathrm{LP}_{01}$ mode compared to the $\mathrm{LP}_{11}$ mode.

\section{Experimental Results}

The tapered fiber bundle is aligned with the TMF and the loss on both directions is measured scanning the input polarization to find the extremes for loss and crosstalk. For the multiplexing loss, light is coupled to each of the input fibers and the power output at the TMF end is measured. As shown in Table 1, a higher multiplexing loss is measured on the HI1060 fibers, which agrees with the lower overlap of $\mathrm{LP}_{11}$ modes as shown in Fig 1(b) . For the de-multiplexing loss measurements, the $\mathrm{LP}_{01}$ mode is launched into the TMF through an SMF splice and the output power of SSMF is $13 \mathrm{~dB}$ higher than that out of the HI1060 fibers. Similarly, LP 11 mode is launched to the TMF using a LPG and the sum of the two HI1060 output is $7 \mathrm{~dB}$ higher than out of SSMF, thus showing selectivity between the two mode groups. This is further confirmed by spatial and spectral imaging $\left(\mathrm{S}^{2}\right)$ of the output modes using a tunable laser and an infrared camera. In this $S^{2}$ method, the Fourier- filter based analyzing technique [3], which assumes a dominant mode, is used. The method works well, as long as the crosstalk is less than $-10 \mathrm{~dB}$. When the light is launched to SSMF, the dominant mode in the TMF is $\mathrm{LP}_{01}$ with low crosstalk to the $\mathrm{LP}_{11}$ mode as shown in Table 1 . With light at each of the HI1060 fibers, $\mathrm{LP}_{11}$ is the dominant mode, also with even lower crosstalk with the $\mathrm{LP}_{01}$ mode as predicted in fig 1 (c).

Table 1. Loss measurements and $\mathrm{S}^{2}$ imaging of the output modes in the multiplexing direction showing polarization dependence in the fabricated lantern

\begin{tabular}{|c|c|c|c|c|c|c|}
\hline & \multirow{2}{*}{\multicolumn{2}{|c|}{$\begin{array}{l}\text { SSMF Input } \\
3 \mathrm{~dB}-3.3 \mathrm{~dB}\end{array}$}} & \multirow{2}{*}{\multicolumn{2}{|c|}{$\begin{array}{c}\text { first HI1060 Input } \\
5.5 \mathrm{~dB}-6.4 \mathrm{~dB}\end{array}$}} & \multirow{2}{*}{\multicolumn{2}{|c|}{$\begin{array}{c}\text { second HI1060 Input } \\
4.9 \mathrm{~dB}-5.2 \mathrm{~dB}\end{array}$}} \\
\hline Multiplexing Loss & & & & & & \\
\hline \multirow{4}{*}{$S^{2}$ results } & Dominant mode & Crosstalk & Dominant mode & Crosstalk & Dominant mode & Crosstalk \\
\hline & & $-14.4 \mathrm{~dB}$ & & $-16.8 \mathrm{~dB}$ & & $-19.9 \mathrm{~dB}$ \\
\hline & & $-15.6 \mathrm{~dB}$ & & $-15.9 \mathrm{~dB}$ & & $-13.9 \mathrm{~dB}$ \\
\hline & & $-16.1 \mathrm{~dB}$ & & $-17.8 \mathrm{~dB}$ & & $-14.4 \mathrm{~dB}$ \\
\hline
\end{tabular}

\section{Conclusion}

We demonstrate the fabrication of a mode selective photonic lantern without the use of a low index cladding. Using $\mathrm{S}^{2}$ imaging a crosstalk around $-15 \mathrm{~dB}$ is measured for multiplexing. By launching the $\mathrm{LP}_{01}$ and $\mathrm{LP}_{11}$ one after the other into the few mode fiber, a crosstalk around $-10 \mathrm{~dB}$ is measured for de-multiplexing.

\section{Acknowledgements}

The Danish Council for Independent research, grant DFF-4184-00433 is acknowledged for the financial support.

\section{References}

1. S. G. Leon-Saval, N. K. Fontaine, R. Amez-Correa, "Photonic lantern as mode multiplexer for multimode optical communications," Opt. Fiber Technol. 35, 46-55 (2017).

2. N. M. Mathew, L. Grüner-Nielsen, M. A Usuga Castaneda, K. Rottwitt, "A Novel Fabrication Method for Photonic Lanterns," Proc. of OFC, paper M4D.4, (2018)

3. J. W Nicholson, A. D. Yablon, J. M. Fini, and M. D. Mermelstein, "Measuring the Modal Content of LargeMode-Area Fibers," IEEE Journ. Selec. Top. on Quantum Electr. 15, $61-70$ (2009). 